\title{
Bento and Buffet: Two Approaches to Flexible Summative Assessment
}

Nicky Didicher

TLHE SAPES Simon Fraser University

This practice-sharing piece outlines two main approaches to flexible summative assessment schemes, including for each approach one example from my practice and another from a published study. The bento approach offers the same assessments to all students but a variety of grade weighting schemes, allowing students to change weighting during the term. The buffet approach offers students choice of individualized assessments from a menu of possibilities and individualized grade weighting. I outline some (dis)advantages of each approach, exploring the dilemma of balance between instructor workload and high-value student learning experiences.

\section{Introduction}

$\mathrm{I}_{\mathrm{t}}^{\mathrm{n}}$

n Higher Education today, teaching-centered and teacher-directed paradigms are slowly giving way to the learning-centered and learner-directed. While Pascarella and Terenzini (2005) conclude that "educational settings and approaches defined by the teacher-centered and teacher-directed paradigm are, if not flawed, at least incomplete and demonstrably less effective than other approaches to education" ( $p$. 646), they recommend incorporation rather than replacement:

The discussion should not be about replacing the old with the new but rather about enhancing the old and augmenting the current array of instructional tools. The challenge is to find ways to encourage the incorporation of these enhancements and new pedagogical approaches into our institutions. (p. 647)

The new approaches Pascarella and Terenzini (and numerous others) emphasize are "innovative, active, collaborative, cooperative, and constructivist" learning (p. 646), and focus more on assessment for learning than on assessment of learning.

Knight (2007) says that summative assessment "as currently practiced, is deeply flawed and not conducive to future learning" (p. 72), and
Gordon (2008) believes that "the assessment industry of the future will be concerned with testing only as it serves and advances education" (p. 4). Much learning-centered teaching in Higher Education in North America is nevertheless still embedded within educational institutions focused on the assessment of learning, requiring instructors to assign grades and often to demonstrate whether our students have reached quantifiable educational goals/learning outcomes. In this paper, I address approaches which postsecondary instructors can use to develop summative assessment practices that will both satisfy administrators and better help our students to become lifelong, active, engaged, critical, selfreflexive learners.

Indeed, summative assessment, even when mainly assessment of learning, should have a beneficial effect on student learning, engagement, and motivation to learn. It should also be valid for purposes linked to learning outcomes and have enough scope to allow students at different levels of mastery to demonstrate their knowledge, understanding, skills, and judgement. Is it possible for summative assessment to be innovative in ways that will promote high-value learner-directed and learning-centered student experiences?

Let us envision a spectrum from fully student-directed learning to fully teacher-directed 
learning. On the student-directed end we have assessment schemes in which each student negotiates major aspects of the grade with the teacher: i.e. tasks, timelines, weightings, methods of assessment (e.g. who does the assessing), and marking criteria. On the more traditional end of this spectrum, we have assessment schemes entirely teacher-determined and uniform for all students in a learning group. Studies such as that by Pacharn, Bay, and Felton (2013) suggest that increasing flexibility in grading systems leads to increased student engagement and learning. However, student-directed assessment, while workable in small cohorts, can be extremely challenging for the class sizes most postsecondary instructors teach. There are numerous possible assessment schemes which range along this spectrum, many of which work well with mid-size classes of 50 to 150 students without overloading the instructor and/or Teaching Assistants (TAs). Workload is important here: both formative assessment and student-directed summative assessment tend to require more time and effort of teachers. I believe that flexible summative assessment offers us the possibility of a balance between workload and effective student learning, between active learning and having demonstrable learning outcomes.

What follows will be a practice sharing of two models of flexible summative assessment, including one example each from my own practice plus another each from the work of others to show additional ways in which flexibility may be implemented in a variety of disciplines. I teach English literature courses with class sizes ranging from 18 to 255 students. I have experimented with different summative assessment schemes that allow flexibility with tasks, timelines, and/or grade weightings, which I group roughly into two types I label "bento" and "buffet." In a bento marking scheme, students choose between several pre-set assessment options that, like bento boxes on a restaurant menu, offer a small number of overall choices but some variety within each option. In a buffet scheme, students individualize choices from a wider assessment menu and may also have responsibility for choosing due dates and the grade weighting for each task. I have not in any experimental way studied the effects on student learning of these assessment schemes versus more teacher-driven ones, nor may I share specific student responses because my own formative surveys were not ones with ethics approval. I will lay out some possibilities, indicating what I perceive to be the main advantages and disadvantages of each approach and why I use the buffet schemes more often.

\section{The Bento Approach}

In the bento assessment scheme I have used, students have identical tasks and due dates, but choose from grade weighting options. For example, in a one-term, third-year course on fantasy and popular culture with 69 students, I assigned everyone four tasks: a written report, an essay, participation, and a final exam. At the beginning of term I asked each student to choose a marking scheme from among the following:

\begin{tabular}{lcccc}
\hline Emphasis & \multicolumn{4}{c}{ Course weighting (\%) } \\
\cline { 2 - 5 } & report & essay & participation & exam \\
\hline Exam & 15 & 25 & 15 & 45 \\
Writing & 25 & 35 & 15 & 25 \\
Participation & 20 & 30 & 25 & 25 \\
\hline
\end{tabular}

In setting the possible grade weightings, I considered what I felt comfortable with as minimums and maximums in each case. I included in my online syllabus details on each of the assessment tasks and my marking criteria for them. I told students at the beginning of term that I would allow them to switch between different grade weighting schemes at any point up to the last day of class. Some students resisted making a choice early during the term, on the grounds that if they could change later then they would wait to see how they were doing before settling on a grading scheme, but I wanted them to consider at the beginning of term issues such as their current strengths and weaknesses, and whether they anticipated absences. My aim was to increase selfreflection while reducing their anxiety, because they knew they could minimize the effects on their final grade of lack of success with any task other than the exam. In this course, I was personally grading all the assignments (and as a larger class with extra contact 
hours it counted as two courses in my teaching load), but this scheme would have worked very well with a TA or TAs doing a large portion of the marking. I did not feel overworked because I was doing exactly the same amount of marking I would have done without allowing them the flexible grade weighting scheme. Also, the assessed work that enabled me to judge whether each student had achieved learning outcomes remained identical to the traditional approach.

Other examples of a bento approach to flexible summative assessment have been published. Cook (2001) offered her students in a large first-year Economics course four different grading schemes, one in which the final exam was worth $100 \%$ of the course mark, and others which included different combinations of mid-term assignments and their course weightings. Students then had the option to complete no mid-term assignments, some, or all of them. Note that this scheme reduced the overall work for the instructor and for students who chose to omit assignments. Software calculated which grading scheme would earn the best grade and assigned that automatically to individuals, but students who chose to write only the exam of course had their grade based solely on that. As one might expect, students who chose to do only the final exam had a much higher rate of failure in the course than those who chose to do one or more mid-term assignments.

This points to one of the disadvantages of most flexible summative assessment schemes: weak students can and often will make poor choices; their grades and presumably their learning suffer because of it. Another disadvantage of the bento approach overall would be that students have limited ways to personalize their learning and may experience less engagement. I find the main advantages of a bento marking scheme are 1) formative assessment, 2) workload, and 3) compassion. The teacher has the opportunity to build formative assessment into any or all of the assignments (e.g. peer reviews, in-class workshops, submission of rough drafts). This may somewhat mitigate poor choices by weak students. There is no increase in workload to the person or people doing the assessing over the standard teacherdirected model. For grade calculation, one can set up an Excel file or other spreadsheet, create different tabs/groups with different calculations, and move students between groups at the end of term, or keep them all in one non-calculated spreadsheet during the term and divide them into units with different calculations later. Students who experience a medical or personal crisis during the term are able to modify the weighting of their grade elements to mitigate the effects of that crisis, thereby introducing a certain amount of compassion into the assessment scheme.

\section{The Buffet Approach}

In the buffet scheme I use, students choose from a menu of assessments and assign individual due dates and grade weightings. Students fill in an agreement form in week two (instructor/TA and student each retain a copy), but they have the opportunity to make certain changes up until a specified date. My rules include not being able to choose any task more than once, not being able to eliminate a task after its deadline, getting approval for a self-developed essay or project topic well before its deadline, and only being able to modify a deadline for non-emergency reasons a week or more in advance. While this particular buffet scheme makes three aspects of assessment flexible-tasks, weightings, and timelines - other variants may use different kinds of flexibility, e.g. offer a buffet of assignments but specify how much each is worth or specify a deadline for each. See, for example, Appendix 1 in LearnerCentered Teaching: Five Key Changes to Practice (Weimer, 2013).

The buffet should contain assessments one knows to offer valid samples of student work which satisfy departmental/institutional criteria. Here is an example from my third-year course on children's literature with an enrolment of 30 :

- final exam, can be worth $20-45 \%$ of final grade

- reading journal, $20-45 \%$

- participation, $10-25 \%$

- research essay, $25-45 \%$

- non-research essay, $20-40 \%$ 
- creative project (either creative writing or in some other medium), 15-30\%

- survey project (reading to a group of children and analyzing their responses), 15$30 \%$

- annotated bibliography on a children's author, $15-30 \%$

- short seminar, $10-25 \%$

- lesson plans for a course text, $10-25 \%$

- storytelling (reading/reciting to the class and leading discussion), $5-10 \%$

From this list students had to choose at least one essay (research or non-research) and at least one breadth component (exam or reading journal), then others as desired. In a larger class I specify the exam and do not offer the journal option because of the extra time it takes to mark them. When I first developed the scheme, I expected many students to do the three-task minimum. However, I found the majority of students overload themselves and their marker(s) with work. I now recommend strongly they choose three or four items from the menu, and discourage attempting more than five. I openly recommend what I see as the best way to work the system: choose three tasks, one with an early due date, and if they are disappointed in their grade on that, reduce its weighting and add another later on. Figure 1 shows the front side of my "evaluation agreement" form, which has specific rules on the back.

I give myself/my TAs a checklist to use when students submit their agreement forms which includes questions such as: does the assessment scheme sum to $100 \%$ ? are the weights within parameters? have they included any due dates after the day designated as the last one possible? When I give my explanation of the marking scheme in the first class, I ask students who have taken similar classes with me to give advice to current students about their choices, and at the end of term each cohort gives written advice to the next. It can be overwhelming for students and TAs at first, so I encourage people to talk to me about their possible choices.

As another example of a buffet approach to flexible summative assessment, I offer that of Zarzeski (1998). For her Intermediate Accounting course there were 400 points for exams and 50 points for a team project, but students could choose from a menu of five other assessment tasks worth between 10 and 70 points with which they could replace up to 70 of the exam points. One third of the students perceived that doing the supplementary assignments helped them do better on tests and exams, and almost all felt they had learned valuable professional skills by doing the supplemental assignments.

There are advantages for both students and teachers when using a buffet approach to summative assessment. Students can focus on their interests and skills, can opt for a challenge/new skill at a lower risk by minimizing the weight for it, can arrange their due dates around work in other courses, and can frontload term work to make life less stressful later. Markers have a constant small pile rather than peaks and valleys (although there is always one large pile on the last possible day), have more varied and more interesting marking, and have students more willing to come for help during office hours-while making changes to their agreement or getting more information about an unusual assessment, they are more likely to ask for support in their learning. There is also the possibility for compassion in this assessment scheme: for students in crisis, a revised agreement sheet can make course completion possible. If the menu contains work the department considers assessable/valid and one's rules provide consistency, institutional approval is readily attained.

There are some disadvantages to the most flexible buffet schemes. Students get no reminders of due dates and are more likely to pile up late penalties. Formative assessment to support students in developing skills they need for the assignments becomes a challenge: when everyone chooses different types of assignments and different due dates, peer reviews and in-class workshops become difficult if not impossible. I do stress the value of bringing rough drafts to me during my office hours. If students make wise choices and schedule early due dates for some assignments, then the term work functions in a way similar to continuous assessment or a portfolio, and provides ongoing formative feedback. As with the bento scheme Cook designed, the weakest students are more likely to make choices detrimental to their 
learning: they make all their assignments due on the last possible day, giving themselves a supposed "buffer zone" while planning to complete some assignments before their contracted date; unfortunately, this usually means they procrastinate, overwork themselves at the end of term, and do not receive feedback from earlier marked work to help them improve on subsequent assignments and exams. The marker's workload increases somewhat in this buffet scheme, but marking is spread throughout the term and, in my opinion, is a manageable trade-off for the advantages of flexibility and student engagement.

The construction of a spreadsheet to calculate grades for a buffet scheme is trickier: one must make a column for each assignment and add rows which program the spreadsheet to calculate percentages for the cell above or below, or do individual calculations.

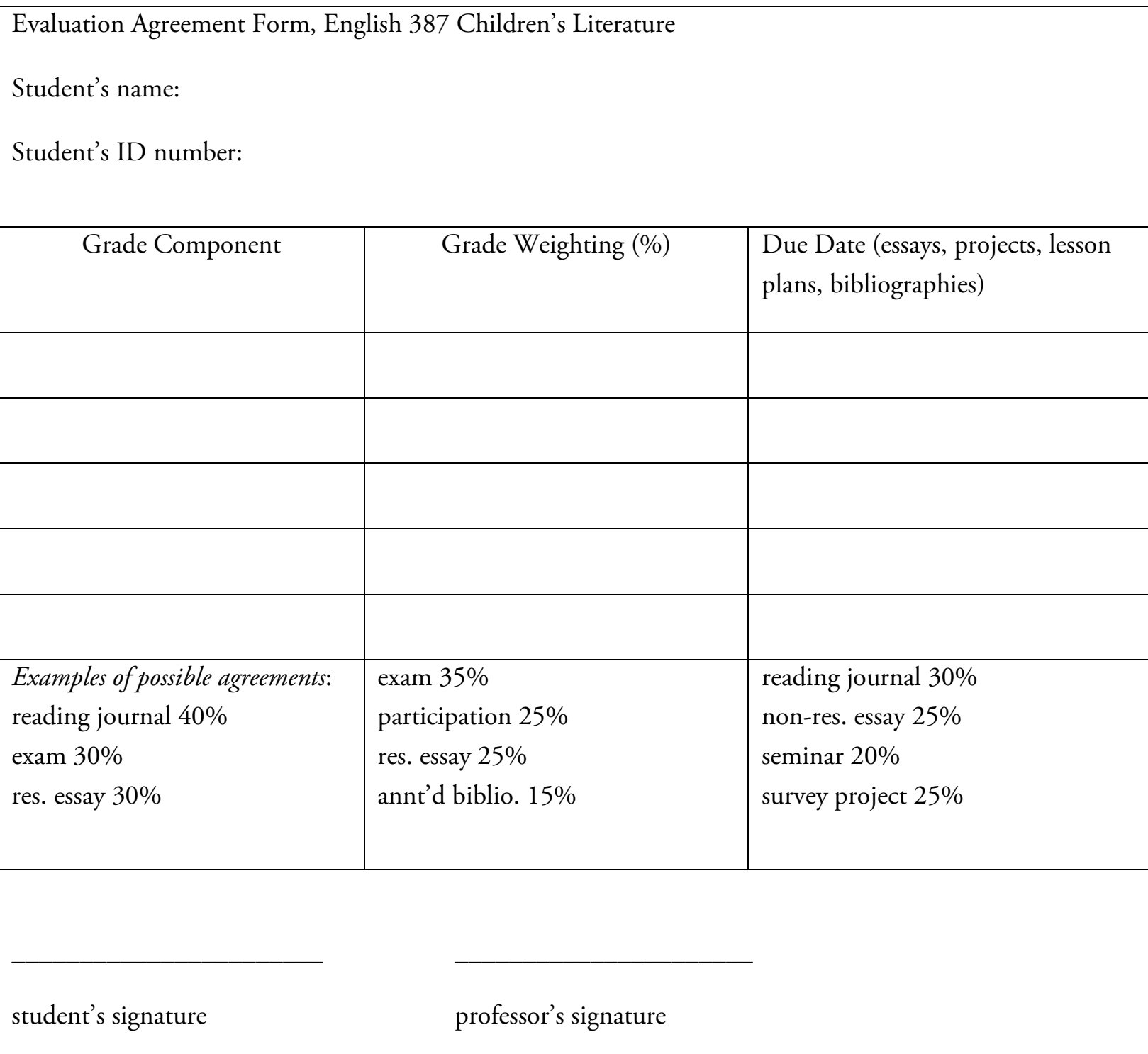

Figure 1

Buffet-style Agreement Form 


\section{Conclusion}

Although I have not analyzed student responses to either the bento or buffet scheme in an ethicsreviewed scholarly study, I can report on impressions collected from student evaluations and exit surveys. Students in both schemes are grateful they can increase weight for successful work and minimize damage caused by failure, but respond more enthusiastically to the buffet approach. On course evaluations, students are more likely to comment positively on the quality and quantity of learning in buffet courses than in bento ones or others I teach with more teacher-centered assessment schemes. I prefer the buffet approach for student engagement and satisfaction, for the variety of marking it gives me, and for its capacity to promote student wellness by lessening stress. Having compassion without sacrificing academic rigour is important to me. More of my time and effort goes into a buffet course than courses using either a bento or a traditional assessment scheme, but not substantially more, and I believe the benefits to me and my students outweigh the extra work.

Instructors interested in problem-solving or experiential learning should find it feasible to adopt flexible summative assessment into their courses, and those who regularly use learningcentered teaching techniques alongside teachercentered assessment will find it rewarding to make summative assessment more flexible. I recommend starting with a small amount of flexibility and gradually finding what creates the best balances for you, your departments/institutions, and your students.

\section{References}

Cook, A. (2001). Assessing the use of flexible assessment. Assessment \& Evaluation in Higher Education, 26(6), 539-549. http://dx.doi.org/10.1080/02602930120 093878 VIEW ITEM
Gordon, E.W. (2008). The transformation of key beliefs that have guided a century of assessment. In C.A. Dwyer (Ed.), The future of assessment: Shaping teaching and learning (pp. 3-6). New York \& London: Lawrence Erlbaum.

Knight, P. (2007) Grading, classifying, and future learning. In D. Boud \& N. Falchikov (Eds.), Rethinking assessment in higher education: Learning for the longer term (pp.72-86). London: Routledge.

Pacharn, P., Bay, D., \& Felton, S. (2013). The impact of a flexible assessment system on students' motivation, performance and attitude. Accounting Education: An International Journal, 22(2), 147-167. http://dx.doi.org/10.1080/09639284.201 3.765292 VIEW ITEM

Pascarella, E.T. \& Terenzini, P.T. (2005). How college affects students: $A$ third decade of research (Vol. 2). San Francisco: JosseyBass.

Weimer, M. (2013). Learner-Centered Teaching: Five Key Changes to Practice (2nd ed.).San Francisco: Jossey-Bass

Zarzeski, M.T. (1998). The use and benefit of flexible student contracts. Issues in Accounting Education, 13(3), 585-594.

\section{Acknowledgements}

I thank my students for their enthusiasm and interest, and for the ways they have responded to and advised me on my methods for teaching and assessment. I also thank Michael Lockett from the Teaching and Learning Centre at SFU for giving me valuable feedback on a draft of this paper. 


\section{Biographies}

Nicky Didicher, $\mathrm{PhD}$ is a Senior Lecturer in the Department of English at Simon Fraser University. She teaches a wide range of undergraduate courses, with specializations in eighteenth-century British literature and children's literature. She is the colead of SFU's Rethinking Teaching Course Design Workshop and is always working to improve the ways she does learning-centered teaching. 


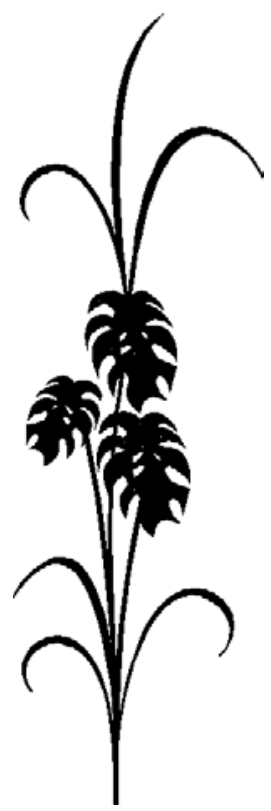

